\title{
124. On the Variation of Magnetic Dip in Central Japan.
}

By Saemon Tarô Nakamura and Yosio Katô.

Physical Institute, Tohoku Imperial University, Sendai.

(Comm. by A. Imamura, M.I.A., Nov. 12, 1985.)

In September 1934, the present writers carried out a magnetic survey with dip circle along the Pacific coast of the central part of Japan. Since then regular observations were repeated six times in the interval ending August 1935. The total number of stations was 26, at 22 of which observation was repeated twice or more.

Secular variation. Since 1887, magnetic surveys in Japan have been repeated by a number of observers. Some examples of the variation in dip thus obtained are shown in Fig. 1.

In the second column of the annexed table is given the secular variation of dip worked out from observations before 1930, and in the third column that worked out from observations after 1934. It will be seen that the regular variation during the last one

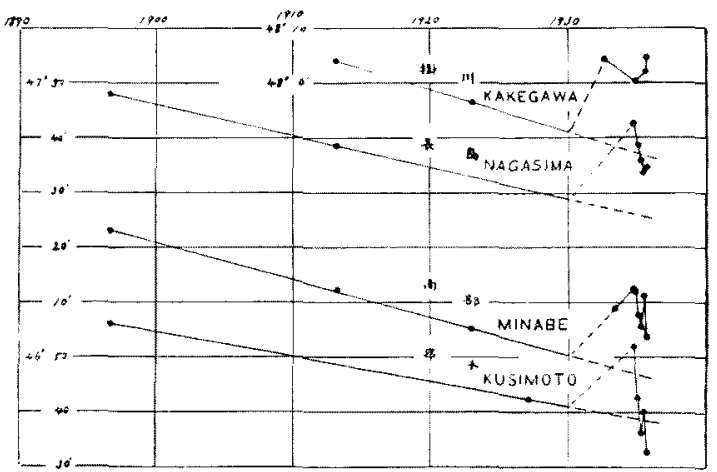

Fig. 1. year is several times greater than that before 1930, and that the number of stations in which secular variation was greater before 1930 , is smaller since 1934 .

In the fourth and fifth columns are given the data of the first observation of the recent survey, while in the sixth column are given corresponding values calculated by extrapolating the data before 1930 . In the last column, the differences of the observed and the calculated values of dip are given. At every station, without exception, the recent values of dip are distinctly larger than those calculated. It seems that the dip in this region, which suddenly increased a little after 1930, attained its maximum in 1932 or 1933 . Since then it decreased again with much greater rapidity than it did before 1930. The cause of this sudden change in dip may be tectonic, although nothing is difinitely known at present.

Short period variation. Besides the general tendency of the rapid decrease above mentioned, there is a fluctation of short period. Fig. 2 shows the geographical distribution of the short period fluctuations.

The figure also shows the epcentres of earthquakes that took place in the corresponding intervals. There is a tendency for earthquakes to occur in regions where the dip is increasing.

In conclusion, the writers wish to express their sincere thanks to 
the Councils of the Tôshôgû Memorial Funds and of the Hattori Gratitude Funds for generous grants made to enable them to carry out the present work.

TABLE.

\begin{tabular}{|c|c|c|c|c|c|c|}
\hline \multirow{2}{*}{ Station } & \multicolumn{2}{|c|}{$\begin{array}{l}\text { Secular Variation } \\
\text { in min./year }\end{array}$} & \multirow{2}{*}{ Date } & \multicolumn{3}{|c|}{ Dip } \\
\hline & $\begin{array}{c}\text { Before } \\
1930\end{array}$ & $\begin{array}{l}\text { After } \\
1934 \\
\end{array}$ & & Obs. & Cal. & Diff. \\
\hline Numadu & -0.499 & -7.05 & 1934.27 & $48^{\circ} 10.4^{\prime}$ & $48^{\circ} 01.8^{\prime}$ & +8.6 \\
\hline Kakegawa & -0.770 & +3.92 & 1934.84 & 4800.3 & 4747.3 & +13.0 \\
\hline Toyohasi & -0.739 & -1.61 & 1934.84 & 4811.4 & 4801.5 & +9.9 \\
\hline Kôwa & -0.327 & -7.56 & 1934.70 & 4821.1 & 4810.7 & +10.4 \\
\hline Kuwana & -0.474 & -10.87 & 1934.67 & 4840.7 & 4822.9 & +17.8 \\
\hline Kameyama & - & - & 1934.67 & 4825.8 & - & - \\
\hline Ieki & - & - & 1934.67 & 4311.2 & - & - \\
\hline Miyagawa & -0.661 & - & 1935.25 & 4752.3 & 4845.2 & +7.1 \\
\hline Sakate & - & -8.09 & 1934.67 & 4708.4 & - & - \\
\hline Kasikozima & - & - & 1935.63 & 4736.9 & - & - \\
\hline Nagasima & -0.575 & -9.07 & 1934.68 & 4742.5 & 4726.0 & +16.5 \\
\hline Kinomoto & - & -17.52 & 1934.69 & 4723.1 & - & - \\
\hline Hongû̀ & - & - & 1934.69 & 4718.5 & - & - \\
\hline Kusimoto & -0.449 & -22.72 & 1634.69 & 4651.9 & 4638.9 & +13.0 \\
\hline Minabe & -0.684 & -7.07 & 1934.69 & 4712.5 & 4657.1 & +15.4 \\
\hline Minosima & - & -8.59 & 1934.69 & 4737.2 & & \\
\hline Ryûzin & - & - & 1934.69 & 4723.9 & - & - \\
\hline Myôzi & 一 & -7.17 & 1934.69 & 4749.0 & - & - \\
\hline Kamiiti & - & -0.89 & 1934.69 & 4751.9 & - & - \\
\hline Nara & - & -12.76 & 1934.69 & 4832.1 & - & - \\
\hline Hirano & - & -6.67 & 1934.70 & 4822.8 & - & - \\
\hline Hatiman & - & -9.33 & 1934.70 & 4849.8 & - & - \\
\hline Tokusima & -0.797 & - & 1935.45 & 4735.2 & 4720.0 & +15.2 \\
\hline Murotozaki & - & - & 1935.44 & 4635.3 & - & - \\
\hline Murotomati & - & - & 1935.44 & 4635.3 & - & - \\
\hline Susaki & -0.762 & - & 1935.45 & 4656.1 & 4644.9 & +11.2 \\
\hline
\end{tabular}


No. 9.] On the Variation of Magnetic Dip in Central Japan.
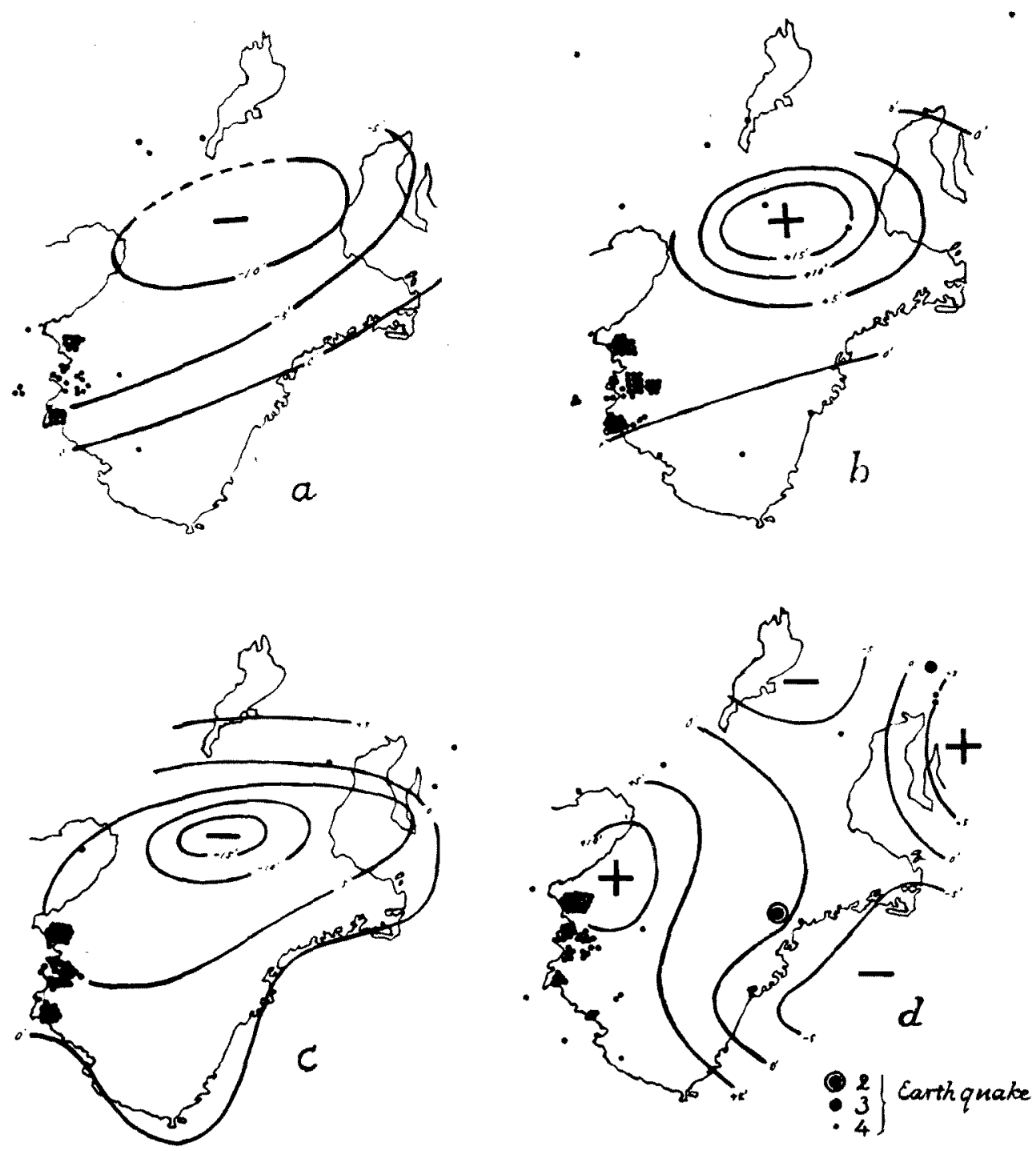

Fig. 2. 